\title{
The Effect of Using Dicto-Gloss as a While-Listening Activity for Listening Comprehension Development of EFL Learners
}

\author{
Maryam Elahifar $\mathbb{D D}^{1}$ Fatemeh Ebrahimi, ${ }^{1}$ and Zeinab Azizi $\mathbb{D}^{2}$ \\ ${ }^{1}$ Department of English Language Teaching, Ahvaz Branch, Islamic Azad University, Ahvaz, Iran \\ ${ }^{2}$ Teaching English and Linguistics Department, University of Ayatollah Ozma Borujerdi, Borujerd, Iran
}

Correspondence should be addressed to Maryam Elahifar; drcharous@yahoo.com

Received 15 November 2021; Revised 3 January 2022; Accepted 5 January 2022; Published 27 January 2022

Academic Editor: Harco Leslie Hendric Spits Warnars

Copyright (C) 2022 Maryam Elahifar et al. This is an open access article distributed under the Creative Commons Attribution License, which permits unrestricted use, distribution, and reproduction in any medium, provided the original work is properly cited.

\begin{abstract}
The present study aimed to investigate the effects of using dicto-gloss as a while-listening activity for improving EFL learners' listening comprehension in Iran. To fulfill the objectives of the study, 80 high school female students were selected using a random sampling method, and they took the Oxford Quick Placement Test (OQPT). A total of 40 students whose scores fell between 1 SD below and above the mean were selected and randomly assigned to the experimental group and control group. Then, the groups went through a pretest, intervention (lasted 10 sessions, held once a week), and posttest procedure. The collected scores were analyzed using an independent sample $t$-test. The findings revealed that the experimental group outperformed the control group. The results indicated that using dicto-gloss as a while-listening activity can improve significantly the Iranian EFL learners' listening comprehension. The study ends with offering some implications.
\end{abstract}

\section{Introduction}

For a long time, the listening comprehension skill did not receive adequate attention in second language (L2) education. It was at the beginning of the 1970s when listening comprehension began to draw the attention of L2 teachers and learners [1]. According to Tyagi [2], successful listening comprehension includes distinguishing between sounds, recognizing the meaning of words, recognizing the grammatical clusters of phrases, recognizing the utterances and sets of statements that make sense, integrating linguistic cues to nonlinguistic and paralinguistic prompts, utilizing background information to anticipate and verify interpretation, and remembering vital thoughts and phrases. The importance of listening comprehension at the early stages of L2 learning lies in the benefits it brings to L2 learners, including cognition, productivity, usefulness, and emotion $[3,4]$.

The intellectual benefit of early listening engagement is that it offers L2 learners more opportunities for acquiring L2 naturally. Listening comprehension should come first because identification knowledge is needed to process and decode auditory data, whereas retrieval information is necessary to encode and create speech [4]. The next advantage of listening comprehension is efficiency, as L2 learning is more efficient when there is no need for learners to speak immediately. The other advantage of listening comprehension is utility or usefulness. It means that usually, we listen more than we speak. The last benefit of listening comprehension is emotive. When L2 learners are obliged to produce early oral output, they get anxious and stressed. Without this pressure, L2 has a relaxed focus on improving listening comprehension, thus assisting the other language skills to emerge [5].

L2 learners who aim to improve their productive skills, as Rost [6] notes, firstly, need to interpret the oral or written input they are exposed to. If L2 learners wish to convey their message across, they must know how to interpret language in real-life settings to grasp the essential meaning of what they are communicating about. As a result, listening comprehension is critical in L2 learning as it provides L2 learners sufficient input [7]. Therefore, it is essential to give particular 
attention to teaching listening comprehension in L2 classes. For this purpose, L2 teachers may implement diverse activities, such as dicto-gloss.

Wajnryb [8] introduced dicto-gloss as a new strategy to improve listening comprehension. It has some similarities to the conventional dictation (hence part of its name), however, it is completely different in terms of goals and implementation. As Murray [9] notes, dicto-gloss assists L2 learners to use their grammar assets to rebuild a text and to be aware of their own inadequacies and requirements. Dictogloss informs L2 learners about their grammatical choices for reconstructing a text. Thus, dicto-gloss is an L2 education strategy that teaches grammatical rules. L2 learners should work in small groups to synthesize a text in the L2 language. Al-Sibai [10] considers dicto-gloss to be a synthesis of conventional and communicative concepts. As Stewart, Rodríguez Silva, and Torres González [11] note, dicto-gloss is rested upon the procedures that are flexible and practical enough, such that it can meet L2 learners' needs, interests, and learning preferences. In addition to that, dicto-gloss activities encourage L2 learners to be active and reflective during the listening processes [12]. Previous studies have demonstrated that the dicto-gloss strategies have been useful to improve language skills [11-14]. The underlying reason for the efficacy of dicto-gloss in improving L2 learning is that it is a systematic multistage activity, where L2 learners are obliged to go through four stages: preparation, dictation, reconstruction, and analysis and correction [11].

Considering the points above, it is essential to explore the effects of dicto-gloss on improving L2 learners in the Iranian context. The fact is that the potential of dicto-gloss in the improvement of Iranian EFL learners in private language institutions has received scant attention. Thus, the present study aims to investigate the effects of dicto-gloss on improving Iranian EFL contexts. It is hoped that the findings of the present study can further our understanding of the efficacy of dicto-gloss as a teaching strategy in the improvement of ELF learners' comprehension.

\section{Theoretical Background}

2.1. Listening Comprehension. Rubin [15] described listening comprehension as "an active process in which a listener chooses and interprets information that comes from auditory and visual clues to explain what is happening and what the speakers are going to express." Listening comprehension, according to Neisser [16], is a temporally constant process in which the listener anticipates what will happen subsequently. Listening comprehension is defined by O'Malley, Chamot, and Kupper [17] as a purposeful and active process in which the listener generates meaning using the clues from contextual information and current knowledge while depending on numerous strategic resources to complete the tasks. According to Mendelsohn [18], some strengths in listening are essential, such as understanding the speaker's purpose and processing linguistic forms, including speech pace and added substances, coping with listening in an interplay, recognizing the entire message enclosed in the discourse, grasping the message without perceiving every word independently, and identifying various genres. Brown [19] admitted that listening comprehension is not only the process of the unidirectional receiving of audible symbols but is also considered to be an interactive process.

2.2. Listening Comprehension Strategies. L2 listening research has changed in recent years to concentrate on how students interpret this input. As a result, identifying the techniques that students use in second language acquisition to cope with hearing challenges has become an important aspect of L2 listening studies. The goal of the L2 listening study is to understand the listener's thought processes and recognize positive and constructive tactics $[20,21]$.

Language learning methods, according to Oxford [22], are the procedures that students use to increase their ability to use knowledge in the target language. Cognitive and metacognitive methods were classified by O'Malley and Chamot [17]. However, a third category, namely, socio-affective, was later added to characterize learning that occurs when students engage with one another, ask the teacher for clarification, or use specific anxiety-reduction tactics $[17,23,24]$.

2.2.1. Cognitive Strategies. Cognitive strategies are problemsolving skills that people use to tackle learning challenges and make the process of obtaining information or skill easier [25]. Cognitive methods are linked to a specific learning activity, and they include constant modifications or the change of learning materials [17]. According to Goh [26], language learners employ cognitive strategies for processing, storing, and recalling new information.

The cognitive activity in language acquisition is divided into two types from a psychological standpoint: cognitive and metacognitive. The first tries to manipulate the content to be learned or employs a specific method for learning the task, while the second entails preparation, supervision, and evaluation [17].

For L2 listening studies, there are two primary techniques: bottom-up and top-down. Bottom-up approaches include word-for-word translation, changing the speaking pace, reiterating the oral text, and focusing on prosodic features of the text $[27,28]$. According to Brown [29], topdown means employing previous knowledge or experience. On the other hand, top-down strategies contain predicting, inferencing, elaborating, and visualization. Brown [29] points out that bottom-up means applying the information that a person has about sounds, the meaning of the words, and discourse makers to assemble the understanding about what is heard at a time. Advanced learners prefer more top-down strategies than beginners [1].

2.2.2. Metacognitive Strategies. Metacognitive strategies, as described by Rubin [30], are tactics used by students to gain control over their learning by organizing, observing, assessing, and adjusting. According to Oxford [22], the deliberate application of metacognitive methods helps students restore focus when they lose it. Despite the necessity of 
self-monitoring and self-evaluation, learners seldom use metacognitive methods. Empirical studies show that there is a crucial difference between the skilled and less-skilled L2 listeners, which is referred to their use of metacognitive strategies (e.g., $[17,31,32])$.

Vandergrift [31] discovered that skilled listeners utilized twice as many metacognitive methods as nonprofessional listeners. Two metacognitive methods are examined in this article. The first focuses on what the speaker says. It is a tactic that allows the audience to concentrate on the speaker's message without being influenced by external factors. The second metacognitive method determines what to pay attention to ahead of time. Selective attention is a method used by listeners to facilitate the understanding process.

2.2.3. Socioaffective Strategies. Socioaffective is the last category of listening comprehension strategies. It aims to elicit and encourage good emotional responses and perspectives toward language acquisition [33]. According to Vandergrift [31], socioaffective tactics are approaches that the listeners employ to interact with others, check knowledge, or reduce fear. These tactics, according to Gardner and MacIntyre [34], are used to exert control over learning situations. They are crucial because the learning setting and the students' social-psychological elements are inextricably linked.

2.3. Dicto-Gloss Strategy. The concept of dicto-gloss is simple: learners listen to a passage or text. Then, they just write down the key words. They are asked to take note as much as possible in the correct order. Language learners are motivated to work with each other in small groups and make a reconstructed version of the text which they have heard before and taken notes on (Smith, 2012). According to Murray [9], the reconstructed text will not be the same as the original version of the text, however, it must be a linguistically acceptable text, similar to the original one based on the style and content. Dicto-gloss differs from dictation since it includes interaction and collaboration. The task employs negotiation, which is useful in the context of second language acquisition [35].

Dicto-gloss is a kind of collaborative listening and writing task that rises oral interaction, communicative competence, and written output by the understanding of the content and organizational structure of the text and its language features. Mehdiabadi and Arabmofrad [36] pointed out that among different tasks that may affect learners' behaviors, such as motivation, anxiety, and sense of responsibility, dicto-gloss is known as one of the famous output-oriented activities that are focus-on-form tasks.

Wajnryb [8] claimed that dicto-gloss tasks are meaningbased tasks that process the meaning more deeply. They do not simply pass the input straight to short-term memory as in standard dictation. Wajnryb [8] also states that "the Learners who regularly engage in dicto-gloss lessons little by little see a refinement in their aural comprehension and note-taking skills." In addition, in dicto-gloss tasks, learners not only listen to the teacher for understanding the text but also are forced to listen to the other learners while working in groups for reconstructing the text and practicing taking notes.

Four phases were outlined by Wajnryb [8]. The first phase is Preparation. This phase is considered to be a warmup in which the topic is introduced and keywords are addressed. The second one is Dictation. During this step, the passage is read by the teacher at normal speed, twice or three times. At the first reading, learners should listen. The second time, learners can take notes about whatever they can catch. If there is a third reading, which Wajnryb [8] advocated, learners have more chances to expand their notes. Reconstruction is the third phase in which learners should work together in small groups to reconstruct the version of the text from their shared notes. Analysis and Correction is the last phase. During this phase, students evaluate and compare their text to that of the other groups' reconstruction texts. The class can debate the discrepancies in the texts, contrast their versions to the original, and make any required adjustments and edits [8]. In this procedure, the learners or the teachers recognize key grammar points or organizational points for discussion and practice [8].

In summary, the literature review so far showed that dicto-gloss has been used across several areas with different student populations, and its employing has a positive impact on students' performance in different skills, especially in listening comprehension. Moreover, the literature showed that there were rare studies about using the dicto-gloss strategy for developing listening comprehension among Iranian EFL learners. Thus, the aim of the present study is to indicate the necessity of doing this research.

2.4. Empirical Studies. In the literature, some studies have explored the effects dicto-gloss on improving L2 learning. Here, to lay the groundwork for the current study, we review critically some of them. In research by Abbasian and Mohammadi [27], the effects of dicto-gloss on improving Iranian EFL writing were investigated. The findings evidenced that the participants' writing skills significantly improved at the end of the instruction. Additionally, Khoii and Pourhassan [33] compared the efficacy of traditional dictation, dicto-comp, and dicto-gloss on improving Iranian EFL learners' learning of the present continuous of $\mathrm{BE}$ and indefinite articles. Their results indicated that the participants receiving instruction through dicto-comp and dictogloss outperformed the participants receiving instruction via the traditional dictation strategy. Moreover, Kooshafar et al. [37] explored the effects of dicto-gloss on Iranian EFL students' writing skills. Their findings revealed that dictogloss had a great impact on improving the students' longterm writing skill compared to the traditional dictation method. Besides, Prince [38] investigated the effects of a dicto-gloss-based task on improving the French ESL learners' memorizing and writing abilities. His results indicated the improvement in the learners' memorizing and writing skills. Furthermore, El-Esery [23] explored the role of dicto-gloss in improving the listening comprehension of EFL learners. Moreover, in a study by Jibir-Daura [39], the 
effects of using dicto-gloss as an interactive method to teach listening comprehension were investigated. He found that dicto-gloss was an effective way of teaching listening comprehension to L2 learners.

As can be implied in the above-reviewed studies, though the effects of dicto-gloss on the development of writing skills have been investigated in the Iranian EFL context, its effects on the improvement of ELF learners' listening comprehension has gained scant attention. Therefore, the impetus of the present study was to disclose the potentials of dicto-gloss in the improvement of Iranian EFL learners' listening comprehension. To meet this purpose, the following research questions were investigated:

(1) Does using dicto-gloss significantly improve Iranian EFL learners' listening comprehension?

(2) Is there any significant difference between the group receiving instruction based on dicto-gloss and the group receiving instruction based traditional dictation method?

\section{Method}

3.1. Participants. The present study was conducted at Besharat High School in Shoushtar City, Iran. A total of 80 intermediate EFL learners were selected by a random sampling method. As Riazi notes, a random sampling method offers an equal opportunity for the individuals in a group of participants to be chosen for a study. The researchers selected the participants because they were available to them. The participants included female students who were in grade 9. They were aged between 15 years and 16 years. The participants were learning English as a foreign language at school two hours a week, and they did not have any opportunity to learn English outside of the walls of the school. To homogenize the students, a Key English Test (KET) was run. The students whose scores fell one 1SD below and above the mean were selected and randomly assigned to the experimental group $(n=20)$ and control group $(n=20)$, respectively. The researchers informed the students that their participation was voluntary and they could withdraw from the study as they wished. Moreover, the researchers ensured the students that their performance during the study would remain confidential and they would be kept informed about the final findings. It should be noted that the first researcher who was familiar with the principles and procedures of the dicto-gloss strategy run the instruction for the experimental group.

3.2. Instruments. To collect the required data, the researcher used three instruments. The first instrument included the OQPT test to homogenize the students. The OQPT test was designed and developed by Oxford University Press and Cambridge ESOL [22], and it is used for English learners of all levels and ages. The paper-pen version of OQPT was used in the current study because of its ease of administration and logistical considerations. It includes 60 questions in multiple-choice format, taking approximately 60 minutes to be answered. It comprises reading, grammar, and vocabulary. It has two main parts: part 1 (questions 1 to 40 ) is taken by all test-takers and is aimed at students who are at or below the advanced level. The second part (questions 41 to 60 ) is taken only by the participants who score more than 35 out of 40 on the first. The test is quickly marked out of 40 or 60 using a simple overlay.

The second instrument entailed two listening comprehension tests administered as the pretest and posttest. The pretest was administered to measure the students' listening comprehension prior to the treatment. The pretest was designed by the researchers. The test consisted of three major parts: (1) true/false conversational questions, including five sentences, (2) writing what you hear involving four short conversations, and (3) conversation information questions with two short answer questions. The students' scores range from 0 to 30. The units were selected from "Tactics for Listening," developed by Jack C. Richards [13] to measure the students' listening comprehension. The posttest was similar to the pretest, including similar items in content and format. The posttest was administered after the treatment to measure the students listening comprehension at the end of the instruction. The only difference between the pretest and posttest was the order of items to avoid the learners' probable recall of the pretest items. The researchers measured the validity of the listening comprehension tests by experts' judgment. In doing so, we recruited well-experienced EFL teachers to assess the tests in terms of their face and content validity. They confirmed that the test enjoyed the required validity. Finally, the researchers piloted the listening comprehension tests on 12 students with the same features of the participants in the main study at another high school. The reliability of the tests was calculated through KR21 formula, and it was 0.85 and 0.76 for pretest and post-test, respectively.

3.3. Data Collection Procedures. The researchers went through some steps to run the present study. At the first step, they administered the OQPT test to homogenize the students. Based on the students' performance, those whose score fell 1 SD below and above the mean were selected and randomly assigned into the experimental and control group. At the second stage, the researchers ran the pretest to measure the students' listening comprehension before the treatment. At the third stage, the first researcher implemented the treatment for the experimental group. It lasted 10 sessions and was held twice a week. At the beginning of each session, a brief explanation was given to the students about the tasks and the procedures. At first, the students had to listen carefully to the audio played by the instructor. Here, they were not allowed to take note of the contents of the audio. Next, the students were instructed that they could take notes while listening to the audio. It was played two or three times based on the students' needs. Since the participants had to listen carefully and take notes, they needed a high level of concentration. Then, the instructor gave time to the participants to recreate the text in their own words, and they also tried to recall as many sequences, details, and vocabulary as possible. They could eliminate their 
misunderstandings or any ambiguity by interacting and sharing ideas with their peers. Finally, after creating their texts, the instructor showed the text of the conversation on the board using a projector. The students could compare and contrast their texts with the original ones. This procedure continued for the rest of the session. For the control group, the instructor played the audio files one or two times, and the students had to recreate the texts. At the last stage, the researchers administered the posttest to measure the participants' listening comprehension.

3.4. Data Analysis. To analyze the collected data, SPSS version 22 was used. Along with the calculation of the descriptive statistics, including mean and standard deviation, Kolmogorov-Smirnov $(\mathrm{K}-\mathrm{S})$ test, an independent sample $t$-test, and a paired sample $t$-test were run. The Kolmogorov-Smirnov (K-S) test was used to check the normality of the data. The independent sample $t$-test and paired sample $t$-test were used to measure the effects of the dicto-gloss strategy on the students' listening comprehension.

\section{Results}

The results are presented in this section. The means of the two groups were computed to summarize the participants' scores in the pretest and posttest. The results of the K-S test for estimating the normality of data are shown in Table 1.

The test distribution is normal, as shown in Table 1. Therefore, independent and paired sample $t$-tests might be used to calculate the data. The descriptive data for the pretest are shown in Table 2.

Table 2 indicates the descriptive statistics of both groups. The mean and standard deviation of both groups are approximately similar in the pretest. In the experimental group, the mean score is 17.00 and the standard deviation is 6.17. In control group, the mean score is 16.10 and the standard deviation is 5.50. It indicates that at the start of the treatment, both groups are almost identical and homogenous. The data was analyzed using an independent sample $t$ test to see if there was any difference between the groups on the pre-test. The findings are shown in Table 3.

Table 3 shows the results of the independent sample $t$ tests for the pretest of the two groups. Since the observed Sig. (2-tailed) .629 is greater than $0.05(p>0.05)$, the difference between the groups is not significant $(p>0.05)$. It can be understood that both groups performed the same in the pretest. In addition, homogeneity was embedded from the beginning in these two groups. The results of the descriptive analysis are shown in Table 4.

Table 4 compares the mean scores of the experimental group and control group in the posttest. The experimental group's mean score is 20.20, and the control group's mean score is 16.47 . The participants in the experimental group outperformed the participants in the control group. In fact, the treatment improved the performance of the EGs. The independent sample $t$-test was done in the posttest. The results are presented in Table 5 .
Table 5 presents the results of the independent sample $t$-test of the posttest for the two groups. As it can be noticed that the Sig. (2-tailed) is less than 0.05, the difference between the groups is significant $(p<0.05)$. Hence, it can be concluded that the two groups are not similar on the posttest.

Table 6 shows the mean and standard deviation for the two groups in pretest and posttest. As it can be seen, the mean and standard deviation in the experimental pretest (17.00) are nearly similar to those in the control group's pretest (16.10), however, the mean of the experimental group's posttest (20.20) is greater than the mean of the control group's posttest (16.45). It can be understood that the difference between the mean in the pre-experimental and postexperimental groups is significant. The paired sample T-test is shown in Table 7.

In Table 7 , the paired sample $t$-test is used to reveal the significant difference between the two experimental groups in posttest and compare the means of the two variables. Since Sig (.000) is less than 0.05, the difference between the posttest and pretest of the experimental group is significant. Since Sig (0.714) is greater than 0.05, the difference between the posttest and pretest of the control group is not significant.

\section{Discussion}

As noted above, the first research question investigated was if using dicto-gloss significantly improved Iranian EFL learners' listening comprehension. The answer to this question was positive. The findings indicated that the students' listening comprehension significantly improved in the posttest compared to the pretest. In reality, the results documented that because of the instruction based on the dicto-gloss strategy, the students could achieve more promising results at the end of the instruction. The students might have found the dicto-gloss strategy as a useful strategy to improve their listening comprehension.

The second research question examined was if there was any significant difference between the group receiving instruction based on dicto-gloss and the group receiving instruction based on the traditional dictation method. The answer to this question was positive, and the study's findings evidenced that the experimental group outweighed the control group on the posttest. The results indicated that compared to the control group instructed based on the traditional dictation, the experimental group could improve their listening comprehension ability significantly. In a sense, because of the systematic instruction, including preparation, dictation, reconstruction, and analysis and correction, the students might have gained the required skills to handle the challenging listening comprehension tasks.

The results of the study are in line with those of Abbasian and Mohammadi [27], indicating that the participants' writing skills significantly improved at the end of the instruction. Additionally, the findings of the study are congruent with those of Khoii and Pourhassan [33], revealing that the participants receiving instruction based on dicto- 
TABLE 1: Results of the one-sample Kolmogorov-Smirnov test.

\begin{tabular}{lccccc}
\hline & & Experimental-pre & Experimental-post & Control-pre & Control-post \\
\hline $\mathrm{N}$ & & 20 & 20 & 20 & 20 \\
& Mean & 17.0000 & 20.2000 & 16.1000 & 16.4750 \\
Normal parameters & Std. Deviation & 6.17081 & 5.90584 & 5.50502 & 4.66080 \\
& Absolute & 0.167 & 0.113 & 0.135 & 0.126 \\
Most extreme differences & Positive & 0.167 & 0.113 & 0.135 & -0.085 \\
& Negative & -0.085 & -0.107 & 0.604 & -0.126 \\
Kolmogorov-Smirnov Z & & 0.747 & 0.507 & 0.563 \\
Asymp. Sig. (2-tailed) & & 0.632 & 0.960 & 0.910 \\
\hline
\end{tabular}

TABLe 2: Results of descriptive statistics (pretest).

\begin{tabular}{lcccc}
\hline Groups & $\mathrm{N}$ & Mean & Std. deviation & Std. error mean \\
\hline Experimental & 20 & 17.0000 & 6.17081 & 1.37984 \\
Control & 20 & 16.1000 & 5.50502 & 1.23096 \\
\hline
\end{tabular}

TABLE 3: Results of independent sample $t$-test (pretest).

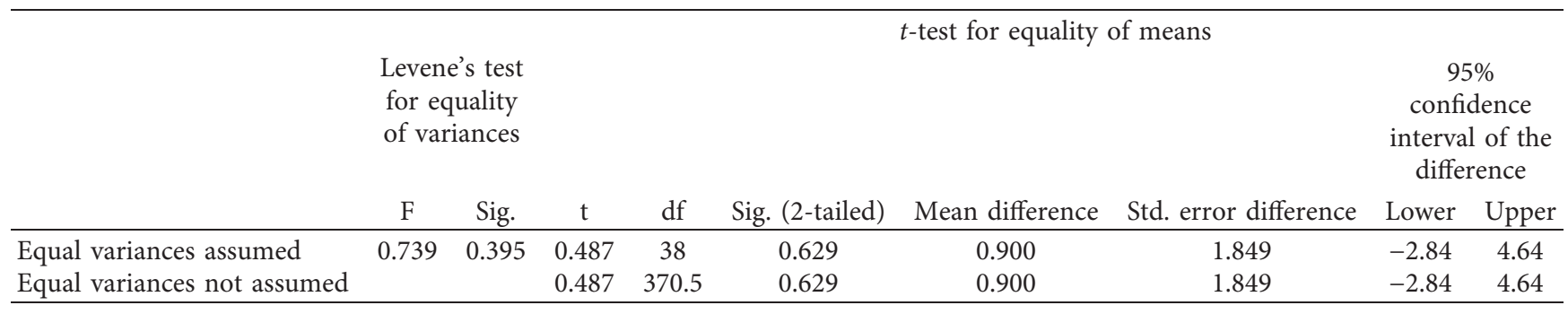

TABLE 4: Results of descriptive statistics (posttest).

\begin{tabular}{lcccc}
\hline Groups & $\mathrm{N}$ & Mean & Std. deviation & Std. error mean \\
\hline Experimental & 20 & 20.2000 & 5.90584 & 1.32059 \\
Control & 20 & 16.4750 & 4.66080 & 1.04219 \\
\hline
\end{tabular}

TABLE 5: Results of independent sample $t$-test (posttest).

\begin{tabular}{|c|c|c|c|c|c|c|c|c|c|}
\hline & \multirow{2}{*}{\multicolumn{2}{|c|}{$\begin{array}{l}\text { Levene's test } \\
\text { for equality } \\
\text { of variances }\end{array}$}} & \multicolumn{7}{|c|}{$t$-test for equality of means } \\
\hline & & & & & & & & $\begin{array}{r}9 \\
\text { confi } \\
\text { interva } \\
\text { diffe }\end{array}$ & $\begin{array}{l}\% \\
\text { lence } \\
\text { of the } \\
\text { ence }\end{array}$ \\
\hline & $\mathrm{F}$ & Sig. & $\mathrm{t}$ & $\mathrm{df}$ & Sig. (2-tailed) & Mean difference & Std. error difference & Lower & Upper \\
\hline Equal variances assumed & 2.185 & 0.148 & 2.214 & 38 & 0.033 & 3.725 & 1.68 & 0.31 & 7.13 \\
\hline Equal variances not assumed & & & 2.214 & 36.0 & 0.033 & 3.725 & 1.68 & 0.31 & 7.13 \\
\hline
\end{tabular}

TABLE 6: Results of descriptive statistics (control vs. experimental pretest).

\begin{tabular}{lccccc}
\hline & & Mean & N & Std. deviation & Std. error mean \\
\hline \multirow{2}{*}{ Pair 1 } & Experimental pretest & 17.0000 & 20 & 6.17081 & 1.37984 \\
& Experimental posttest & 20.2000 & 20 & 5.90584 & 1.32059 \\
\hline \multirow{2}{*}{ Pair 2 } & Control pretest & 16.1000 & 20 & 5.50502 & 1.23096 \\
& Control posttest & 16.4750 & 20 & 4.66080 & 1.04219 \\
\hline
\end{tabular}


TABLE 7: Results of paired sample $t$-test.

\begin{tabular}{|c|c|c|c|c|c|c|c|c|c|}
\hline & & \multicolumn{3}{|c|}{ Paired differences } & \multicolumn{2}{|c|}{$\begin{array}{l}\text { 95\% confidence } \\
\text { interval of the } \\
\text { difference }\end{array}$} & \multirow[t]{2}{*}{$\mathrm{t}$} & \multirow[t]{2}{*}{ Df } & \multirow[t]{2}{*}{ Sig. (2-tailed) } \\
\hline & & Mean & Std. deviation & Std. error mean & Lower & Upper & & & \\
\hline Pair 1 & Exp. pre and post & -3.20 & 2.13 & 0.47 & -4.19 & -2.205 & -6.699 & 19 & 0.000 \\
\hline Pair 2 & Control pre and post & -0.375 & 4.51 & 1.00 & -2.48 & 1.73 & -0.371 & 19 & 0.714 \\
\hline
\end{tabular}

comp and dicto-gloss outperformed the participants receiving instruction via the traditional dictation strategy. Moreover, the study's findings are in agreement with those of Kooshafar et al. [37], documenting that dicto-gloss had a great impact on improving the students' long-term writing skill compared to the traditional dictation method. Besides, the study's results are consistent with the findings of Prince [38]. His results indicated the improvement in the learners' memorizing and writing skills. Furthermore, the study's findings are compatible with those of El-Esery [23], revealing the positive role of dicto-gloss in improving the listening comprehension of EFL learners. Finally, the findings of the study lend support to those of Jibir-Daura [39], indicating that dicto-gloss was an effective way in teaching listening comprehension to L2 learners.

One possible explanation for the findings may be associated with the systematic procedure implemented for the experimental group. At the first stage, when the instructor prepared the students by informing them about the type of the task and the topic they were going to listen to, this might have activated the students' background knowledge. This, in turn, might have assisted the students to make rational connections between the new information and the previous information stored in the students' long-term memory, leading to meaningful learning [40]. Additionally, along with the noticing hypothesis, it may be argued that as the student got prepared to enter the main task, their consciousness might have raised, and they might have given more attention to the listening comprehension tasks [41, 42]. In this regard, it is reasonable to argue that the experimental group received more input, leading to the consolidation of their interlanguage system. Moreover, another line of discussion for the findings may be attributed to the fact that at the second stage, the instructor replayed the audio file as much as the students found it comprehensible. This, accordingly, might have assisted the students to change the input into intake, improving their interlanguage system. As opposed to the control group, the experimental group had this opportunity to modify the input to become compressible.

To discuss the findings more, it may be argued that during the reconstruction phase, the students could work in groups to generate their versions of the original texts [4]. This, in turn, might have offered the students the chance for understanding the essence of the text and creating the correct grammatical structures. In a collaborative environment, the participants could recreate the text in their own words, trying to recall as many sequences and details as possible. When the students encountered doubts in their competence to recreate the text, they might have turned to their peers to remove their doubts. Moreover, in line with the results of the study carried out by Stewart et al. [11], it might be argued that during the reconstruction stage, the instructor might have gained a clear insight into what the students could recall from the original text. Accordingly, the instructor might have used this clue to determine if the students were keeping up or whether further instruction was needed.

The other line of the discussion for the findings might be ascribed to the effects of the analysis and correction phase. During this stage, as the students self-assessed their own texts and formed groups to conduct peer assessments, they might have noticed the differences between their own texts and the original in terms of form, meaning, and language use. As Tsauri [14] argues, in the analysis and correction phase, the students took a more active role, relying on their individual strengths to collaborate and correct each other. In other words, constructive criticism through peer support and teacher guidance might have helped form relationships encouraging students to collaborate and cooperate through social interaction to achieve more promising results [11].

The final justification for the findings may be related to this view that during the instruction, the students might have experienced giving and receiving peer feedback. It might have been a new way of realizing how much they had learned which in turn motivated them to become more aware of their increased knowledge and ability [11]. To close, as the dicto-gloss procedure was implemented, the experimental group might have interacted and supported each other more over time. As a result, they might have accepted responsibility for not only their personal learning but also the learning of their classmates.

\section{Conclusions and Implications}

As noted above, the present study purported to investigate the effects of the dicto-gloss strategy on improving Iranian high school students' listening comprehension. The findings documented that the dicto-gloss strategy could improve significantly the EFL learners' listening comprehension. The findings indicated that as the procedures of the dicto-gloss strategy are implemented well, it can result in the improvement of EFL learners' listening comprehension. Based on the findings, it can be concluded when the EFL learners are prepared well for the task. The text is dictated well. EFL learners reconstruct the texts. They work together to analyze their performance in cooperation with their peers, and their listening comprehension is promoted significantly. 
The results of the study may have some implications for different stakeholders. Firstly, the material developers should consider the dicto-gloss strategy as an effective strategy to improve listening comprehension and include it in English coursebooks. Secondly, teacher educators need to make EFL teachers familiar with the theoretical underpinnings and practical applications of the dicto-gloss strategy. They should help the EFL teacher know how to go through the multistage procedure of dicto-gloss strategy to facilitate EFL learners. Thirdly, EFL teachers should practice dictogloss strategy in their classroom. In doing so, they need to go through the multistage procedure, including preparation, dictation, reconstruction, and analysis and correction. The fourth point is that EFL teachers should get their students to implement the dicto-gloss strategy in pairs and groups such that they become autonomous in using it when the EFL teachers are not available. Finally, EFL learners should know that to improve their listening comprehension, they must practice strategies, such as the dicto-gloss strategy, that are based on the robust theoretical underpinnings and can bring about promising results.

Considering the limitations imposed on the current study, some suggestions for further research are presented. As the current study was conducted just in one state high school, more studies need to be carried out in different parts of the country to increase the generalizability of the findings. Additionally, since the sample of the present study was selected from female high school students, interested researchers can explore the effects of the dicto-gloss strategy on improving male EFL learners' listening comprehension. Furthermore, as the present study included high school students, future studies can select participants from private language institutes and higher education centers. Besides, as the present study was quantitative, qualitative studies can be carried out to disclose EFL learners' perceptions of the efficacy of the dicto-gloss strategy to improve L2 learning. Finally, a micgentic study can be run to show how the dictogloss strategy leads to improving EFL learners' L2 learning by moment-to-moment analysis.

\section{Data Availability}

The data that support the findings of this study are available from the corresponding author upon reasonable request.

\section{Conflicts of Interest}

The authors declare that they have no conflicts of interest.

\section{References}

[1] B. Mowlaie, M. Abdolmajid, and A. Rahimi, "The partial dictation vs. Dictogloss effect on listening comprehension of Iranian EFL learners," Global Journal of Foreign Language Teaching, vol. 10, no. 4, pp. 224-240, 2020.

[2] B. Tyagi, "Listening: an important skill and its various aspects," An International Journal in English, vol. 8, 2013.

[3] J. O. Gary, "Delayed oral practice in initial stages of second languages learning," in New Direction in Second Language Learning, Teaching, and Bilingual Education, M. K. Burt and
H. C. Dulay, Eds., pp. 89-95, TESOL, Washington, DC, USA, 1975.

[4] A. P. Gilakjani and N. B. Sabouri, "The significance of listening comprehension in English language teaching," Theory and Practice in Language Studies, vol. 6, no. 8, p. 1670, 2016.

[5] N. Yildiz and M. Albay, "Factors affecting listening comprehension and strategies for improvement: a case study," International Journal of Social Sciences \& Educational Studies, vol. 2, no. 1, p. 20, 2015.

[6] M. Rost, Introducing Listening, Penguin Books, London, UK, 1994.

[7] T. Kurita, "Issues in second language listening comprehension and the pedagogical implications," Accents Asia, vol. 5, no. 1, pp. 30-44, 2012.

[8] R. Wajnryb, Grammar Dictation, Oxford University Press, Oxford, UK, 1990.

[9] S. Murray, "Dicto-gloss expanded," MET Journal, vol. 10, no. 3, pp. 1-19, 2001.

[10] D. M. M. Al-Sibai, Using Dicto-Gloss Tasks: Attention to Form in a Collaborative Classroom Activity with Female Students at King Saud University, http://mpazhou.ir/wpcontent/uploads/Characteristics-of-Dictation-Tests.pdf M. A. thesis, King Saud University, Riyadh, Saudi Arabia, 2008, http://mpazhou.ir/wp-content/uploads/Characteristicsof-Dictation-Tests.pdf M. A. thesis.

[11] B. L. Stewart, L. H. Rodríguez Silva, and J. A. Torres González, "Integrating language skills through a dictogloss procedure," US Department of State. Bureau of Educational and Cultural Affairs, vol. 52, no. 2, p. 12, 2014.

[12] Z. Vasiljevic, "Dictogloss as an interactive method of teaching listening comprehension to L2 learners," English Language Teaching, vol. 3, no. 1, pp. 41-52, 2010.

[13] G. Jacobs and J. Small, "Combining dictogloss and cooperative learning to promote language learning," The Reading Matrix, vol. 3, no. 1, 2003.

[14] S. S. Tsauri, “The effects of dicto-gloss on students' listening achievement," Jurnal PAJAR (Pendidikan Dan Pengajaran), vol. 5, no. 2, pp. 262-269, 2021.

[15] J. K. Rubin, "A review of second language listening comprehension research," The Modern Language Journal, vol. 78, no. 2, pp. 199-221, 1995.

[16] U. Neisser, Cognition and Reality: Principles and Implications of Cognitive Psychology, W. H. Freeman, San Francisco, CA, USA, 1976.

[17] J. M. O'Malley and A. U. Chamot, Learning Strategies in Second Language Acquisition, Cambridge University Press, Cambridge, UK, 1990.

[18] D. J. Mendelsohn, Learning to Listen: A Strategy-Based Approach for the Second Language Learner, Dominie Press, San Diego, CA, USA, 1994.

[19] H. D. Brown, Teaching by Principles: An Interactive Approach to Language Pedagogy, Longman, New York, NY, USA, second edition, 2001.

[20] S. Lindstromberg, J. Eyckmans, and R. Connabeer, "A modified dictogloss for helping learners remember L2 academic English formulaic sequences for use in later writing," English for Specific Purposes, vol. 41, pp. 12-21, 2016.

[21] M. Zohrabi and Z. Tahmasebi, "A Study of the effect of Dictogloss as a medium of form-focused instruction on vocabulary versus grammar development of Iranian EFL learners," Applied Research on English Language, vol. 9, no. 2, pp. 183-204, 2020.

[22] R. Oxford, Language Learning Strategies: What Every Teacher Should Know, Newbury House, NewYork, NY, USA, 1990. 
[23] A. M. El-Esery, "Dicto-gloss-Based activities for developing EFL learners' listening comprehension," International Journal of English Language Teaching, vol. 4, no. 10, pp. 42-51, 2016.

[24] S. Lapkin and M. Swain, "Focus on form through collaborative dialogue: exploring task effects," in Researching Pedagogic Tasks, pp. 109-128, Routledge, England, UK, 2013.

[25] S. J. Derry and D. A. Murphy, "Designing systems that train learning ability: from theory to practice," Review of Educational Research, vol. 56, no. 1, pp. 1-39, 1986.

[26] C. C. M. Goh, "How ESL learners with different listening abilities use comprehension strategies and tactics," Language Teaching Research, vol. 2, no. 2, pp. 124-147, 1998.

[27] G. R. Abbasian and M. Mohammadi, "The effectiveness of dicto-gloss in developing general writing skill of Iranian intermediate EFL learners," Journal of Language Teaching and Research, vol. 4, no. 6, pp. 1371-1380, 2013.

[28] S. Idek and L. L. Fong, "The Use of Dictogloss as an Information Gap Task in Exploiting Dual Application Principle in Learning Irregular Verbs," Journal of Management Research, vol. 7, no. 2, p. 481, 2015.

[29] S. Brown, Teaching Listening, Cambridge University, Cambridge, UK, 2006.

[30] J. Rubin, "Learner strategies: theoretical assumptions, research history and typology," in Learner Strategies in Language Learning, L. Wenden and J. Rubin, Eds., pp. 15-30, Prentice-Hall, Englewood Cliffs, NJ, USA, 1987.

[31] L. Vandergrift, "Orchestrating Strategy Use: Toward a Model of the Skilled Second Language Listener," Language Learning, vol. 53, no. 3, pp. 463-496, 2003.

[32] W. Widiasmara, Teaching Listening Skill through Dicto-Gloss Technique, http://repository.upi.edu/skripsiview.php?no_ skripsi=11169, Unversity Pendidikan, Indonesia, 2012, http://repository.upi.edu/skripsiview.php?no_skripsi=11169.

[33] Khoii, R., Pourhassan, E. (2015). Effects of Different Types of Dictation Practice on Immediate and Delayed Performance Tests of Present Tense "To Be" Verbs and Indefinite Articles. Retrieved from http://www.academia.edu/4195113.

[34] R. C. Gardner and P. D. MacIntyre, "A student's contributions to second language learning. Part I: Cognitive variables," Language Teaching, vol. 25, no. 4, pp. 211-220, 1992.

[35] T. Nabei, "Dicto-gloss: is it an effective learning task?" Working Papers in Educational Linguistics, vol. 12, no. 1, pp. 31-37, 1996.

[36] F. Mehdiabadi and A. Arabmofrad, "The Effectiveness of Collaborative Output Task of Dictogloss in Enhancing EFL learners' Emotional Intelligence," International Journal of Linguistics, vol. 6, no. 6, pp. 128-142, 2014.

[37] M. Kooshafar, M. Youhanaee, and Z. Amirian, "The effectiveness of dicto-gloss technique on learners' writing improvement in terms of writing coherent texts," Journal of Language Teaching and Research, vol. 3, no. 4, pp. 716-721, 2012.

[38] P. Prince, "Listening, remembering, writing: Exploring the dictogloss task," Language Teaching Research, vol. 17, no. 4, pp. 486-500, 2013.

[39] R. Jibir-Daura, "Using Dictogloss As An Interactive Method Of Teaching Listening Comprehension," Advances in Language and Literary Studies, vol. 4, no. 2, pp. 112-116, 2013.

[40] R. E. Mayer, "Rote versus meaningful learning," Theory Into Practice, vol. 41, no. 4, pp. 226-232, 2002.

[41] R. P. Leow, "Noticing Hypothesis," The TESOL Encyclopedia of English Language Teaching, vol. 8, pp. 1-6, 2018.
[42] M. Sarkhosh, M. Soleimani, and J. Abdeli, "A closer look at Noticing Hypothesis and Focus on form: an overview," International Journal of Linguistics, vol. 4, no. 3, p. 179, 2012. 